Article

\title{
Supervised Classification of Benthic Reflectance in Shallow Subtropical Waters Using a Generalized Pixel-Based Classifier across a Time Series
}

\author{
Tara Blakey $^{1}$, Assefa Melesse ${ }^{1, *}$ and Margaret O. Hall ${ }^{2}$
}

1 Department of Earth and Environment, Florida International University, Miami, FL 33199, USA; E-Mail: tblakey@fiu.edu

2 Florida Fish and Wildlife Research Institute, St. Petersburg, FL 33701, USA;

E-Mail: Penny.Hall@myfwc.com

* Author to whom correspondence should be addressed; E-Mail: melessea@fiu.edu; Tel.: +1-305-348-1930; Fax: +1-305-348-6137.

Academic Editors: Alisa L. Gallant, Deepak R. Mishra and Prasad S. Thenkabail

Received: 2 February 2015 / Accepted: 20 April 2015 / Published: 24 April 2015

\begin{abstract}
We tested a supervised classification approach with Landsat 5 Thematic Mapper (TM) data for time-series mapping of seagrass in a subtropical lagoon. Seagrass meadows are an integral link between marine and inland ecosystems and are at risk from upstream processes such as runoff and erosion. Despite the prevalence of image-specific approaches, the classification accuracies we achieved show that pixel-based spectral classes may be generalized and applied to a time series of images that were not included in the classifier training. We employed in-situ data on seagrass abundance from 2007 to 2011 to train and validate a classification model. We created depth-invariant bands from TM bands 1, 2, and 3 to correct for variations in water column depth prior to building the classification model. In-situ data showed mean total seagrass cover remained relatively stable over the study area and period, with seagrass cover generally denser in the west than the east. Our approach achieved mapping accuracies (67\% and $76 \%$ for two validation years) comparable with those attained using spectral libraries, but was simpler to implement. We produced a series of annual maps illustrating inter-annual variability in seagrass occurrence. Accuracies may be improved in future work by better addressing the spatial mismatch between pixel size of remotely sensed data and footprint of field data and by employing atmospheric correction techniques that normalize reflectances across images.
\end{abstract}


Keywords: benthic reflectance; supervised classification; Landsat; Florida Bay; seagrass landscapes; long-term monitoring

\section{Introduction}

Seagrass meadows are an intricate link between inland and marine ecosystems. In subtropical and tropical estuaries and coastal lagoons, large contiguous seagrass meadows support a range of ecosystem services including nutrient cycling, nursery grounds for many fish and crustacean species, food for endangered large grazers, such as dugong and turtles, and coastal protection by sediment accretion and stabilization [1-3]. Seagrasses are productive carbon fixers [4,5], which places their economic value among the highest of the world's ecosystems [6]. Seagrasses are threatened by a variety of upstream processes, and the loss or reduction in the capacity of seagrasses to perform ecosystem services will influence the balance of adjoining ecosystems, such as coral reefs. Conservation of seagrasses requires management that addresses the spatially and temporally variable nature of hydrologic discharges at coasts.

Seagrass meadows grow at the nexus of terrestrial and marine environments and are impacted by highly dynamic anthropogenic and natural factors. Despite their environmental and economic significance, seagrass populations are threatened worldwide by coastal development and eutrophication and may be nearing a crisis with respect to global sustainability [7]. The land-water interaction along coasts is influenced by freshwater networks where hydrologic impacts to seagrass ecosystems include increases in nutrients such as nitrogen and phosphorus occurring from industrial or agricultural sources [8], sediment discharge from watershed deforestation and mangrove clearing [8], and disruption of the natural salinity regime [2,9]. Without appropriate management, widespread loss of seagrass habitats is predicted to continue [10], especially given continued development of coastal lands.

Researchers and managers would benefit from maps showing temporal changes in the density and distribution of seagrass cover to help inform decisions for minimizing negative impacts to seagrass resources. Continued study of coastal landscape dynamics with accurate, quantitative measurements of areal extent and density of seagrasses is needed to better understand the mosaic of their distribution (degree of patchiness, gap dynamics, habitat edge type, and connectivity) in conjunction with the temporal and spatial variability of hydrologic inputs to coastal areas [7]. Characterizing these dynamics from a synoptic, repeatable perspective with remotely sensed data [11] can strongly augment more accurate point measures of change derived in-situ [12].

Long-term, global archives of satellite multispectral imagery are now readily accessible; yet, the data are not widely used for thematic mapping of benthic cover [13]. Intensive field and laboratory data collection campaigns have been undertaken to calibrate satellite-based retrospective benthos mapping and to validate products used for time series analysis, but the amount of research exploiting satellite archives could be increased if less costly benthic mapping methodologies were identified. The archive of the Landsat 5 Thematic Mapper (TM) sensor offers multispectral imagery at $30 \mathrm{~m}$ spatial resolution at 16-day intervals from 1984 to 2011 and currently is an underutilized global resource for long-term data on coastal environments. The long and consistent record provides an opportunity for 
scientists to retrieve information from periods of time where no other forms of quantitative data are available, making the archive especially valuable in understanding seagrass habitats and coastal dynamics.

Approaches for mapping seagrasses in optically shallow water bodies have evolved from visual interpretation of aerial photography to semi-automated mapping from high resolution airborne or satellite image datasets in association with field-survey and hydro-optical data [14]. A relatively simple and widely used approach for creating seagrass maps is image-specific, pixel-based supervised classification where training pixels are selected to represent each of the classes being mapped and an algorithm matches the spectral properties of image pixels to the most similar, pre-defined, class. Whereas field data are required to ensure appropriate selection of training pixels, this method may be carried out without additional hydro-optical data from the field or lab.

Maps produced from Landsat data and pixel-based supervised classification have been demonstrated to appropriately represent the spatial characteristics of seagrass meadows. Seagrass cover was mapped in Moreton Bay, Australia, by Roelfsema et al. [15] with training pixels for five different seagrass cover classes extracted from a Landsat 5 image of the Bay. Results showed that $>75 \%$ of the Bay was mapped with high categorical reliability. Wabnitz et al. [16] tested the feasibility of achieving large-scale seagrass mapping for the Wider Caribbean region with limited ground truth data, obtaining an average overall accuracy of $68 \%$ across sites for the three-class scheme. Pu et al. [17] mapped seagrass along the western coast of Florida using Landsat 5 data to calculate depth-invariant bands and achieved a $93 \%$ and $66 \%$ overall accuracy for their three-class and five-class schemes, respectively. However, the applicability of the pixel-based classifier in producing a time series of benthic map products was not tested in these studies.

Time series maps of seagrass abundance have recently been produced from Landsat 5 data and pixelbased classification [18-20] using image-specific training areas so that each date in the series is associated with a unique classifier. The "quality" and relevance of classes derived from satellite data are variable across images [21] so that transferring pixel-based definitions of class spectra to other images has been considered impractical [11]. Constraining class definitions to the image in which training pixels are identified, however, limits the resulting multi-temporal analysis to dates where in-situ or other ground truth source is available for the selection of calibration data.

To be as objective as possible and increase the capacity for multi-temporal and multi-site comparison of classification results it is necessary to decouple field work and satellite sensor imaging [22] such as through the use of a spectral library. In the spectral library approach, remote sensing reflectance of individual pixels are compared with simulated spectra created using measured values of bottom reflectance and water inherent optical properties [23]. The spectral library method requires specialized equipment to capture the bottom reflectances and optical properties specific to the study site as well as a radiative transfer model to simulate the spectra of varying water columns over different substrates [22-27]. Although the spectral library method is objective and repeatable, the high degree of expertise and optical data required to define the library may be unattainable in the near term for many seagrass systems. Further, studies have indicated that image-based classification provides similar or even higher accuracy benthic maps compared to the spectral library method [28,29].

A study by Lyons et al. [30] demonstrated that image-based classification methods are applicable to periods without concurrent in-situ data so that long term seagrass maps over the entire Landsat record can be produced allowing management agencies to build a baseline assessment of their resources, 
understand past changes and help inform implementation and planning of management policy to address potential future changes. Instead of pixel-based methods, the object-based supervised classification applied by Lyons et al. [30] was guided by hierarchical rule sets, which achieved an overall classification accuracy of approximately $65 \%$. The thresholds and membership functions in the rule sets were manually adjusted for each image. Although this research illustrated the utility of time-series seagrass maps produced without intensive data collection, the work also indicated a need for mapping methodologies that can improve upon transferability between image dates. Although object-oriented classification can greatly improve accuracy compared with traditional supervised classification, the difficulty in applying the rule-based system for seagrass habitats requires further study to test the appropriateness of object-based classification in the successful extraction of seagrass features [31].

The seagrass meadows mapped in this study are located in Florida Bay, a shallow semi-enclosed estuary in South Florida. The Florida Bay ecosystem has experienced large changes in water quality concurrent with massive die-offs of seagrasses [32]. In 1987 approximately $40 \mathrm{~km}^{2}$ of Thalassia testudinum meadows experienced a major "die-off" in Florida Bay, and that die-off has been followed by smaller $\left(<1 \mathrm{~km}^{2}\right)$ patchy episodes of mortality on an annual basis [1].

Despite tremendous losses suffered in the past 30 years, South Florida still supports roughly 55\%-65\% of Florida's seagrass resources and the greatest population densities on the state's coastline [33]. The Florida Bay seagrass meadows are intricately linked to the reefs of the Florida Keys, a popular tourist destination with approximately 2.5 million visitors annually generating nearly $\$ 1.2$ billion for the region [32]. Although the Florida Bay seagrass landscape is an invaluable cultural and economic resource, a consensus on the primary cause of seagrass losses there has never been ascertained [33]. Therefore, the study area is representative of coastal systems that require better understanding to characterize, monitor and analyze seagrass landscape dynamics to support resource management decisions.

The underlying motivation for this work was to promote the development of remote sensing techniques that can be easily and objectively applied to the span of Landsat 5 images, including periods for which no ground truth data are available, to encourage greater interpretation of satellite archives for resource management. More specifically, a pixel-based classifier trained using ground truthed pixels compiled from three recent images was applied to a series of older images to test the transferability of the image-based spectral characterizations of classes. This work focused on using widely accessible practices to complete the tasks of: (1) normalizing the various dates of satellite data to ensure comparability of the spectral profiles across dates; and (2) defining seagrass classes that are spectrally separable and ecologically relevant.

\section{Data and Methods}

\subsection{Study Site}

Florida Bay is a shallow, sub-tropical lagoon bordered to the north by the southern tip of the Florida Peninsula and to the south and east by the nearly contiguous islands of the Florida Keys (Figure 1). Tidal range throughout the bay is minimal, as physical formations limit exchange with the Gulf of Mexico and Atlantic Ocean, including a series of natural, carbonate mudbanks that divide the bay into numerous shallow basins further reducing water exchange within the system [34]. Winds in the study area are from 
the east from fall through spring, with the strength of wind forcing and the current response decreasing in spring [35]. Along the Southwest Florida Shelf immediately west of Florida Bay, the long-term mean flow is toward the southeast, with seasonal variation in wind forcing resulting in maximum outflows from Florida Bay through the Keys in winter and spring following cold front passages associated with winds toward the east. Minimum outflows occur in the fall when winds toward the west are frequent and inflow across the Keys to Florida Bay can persist for several days [36].
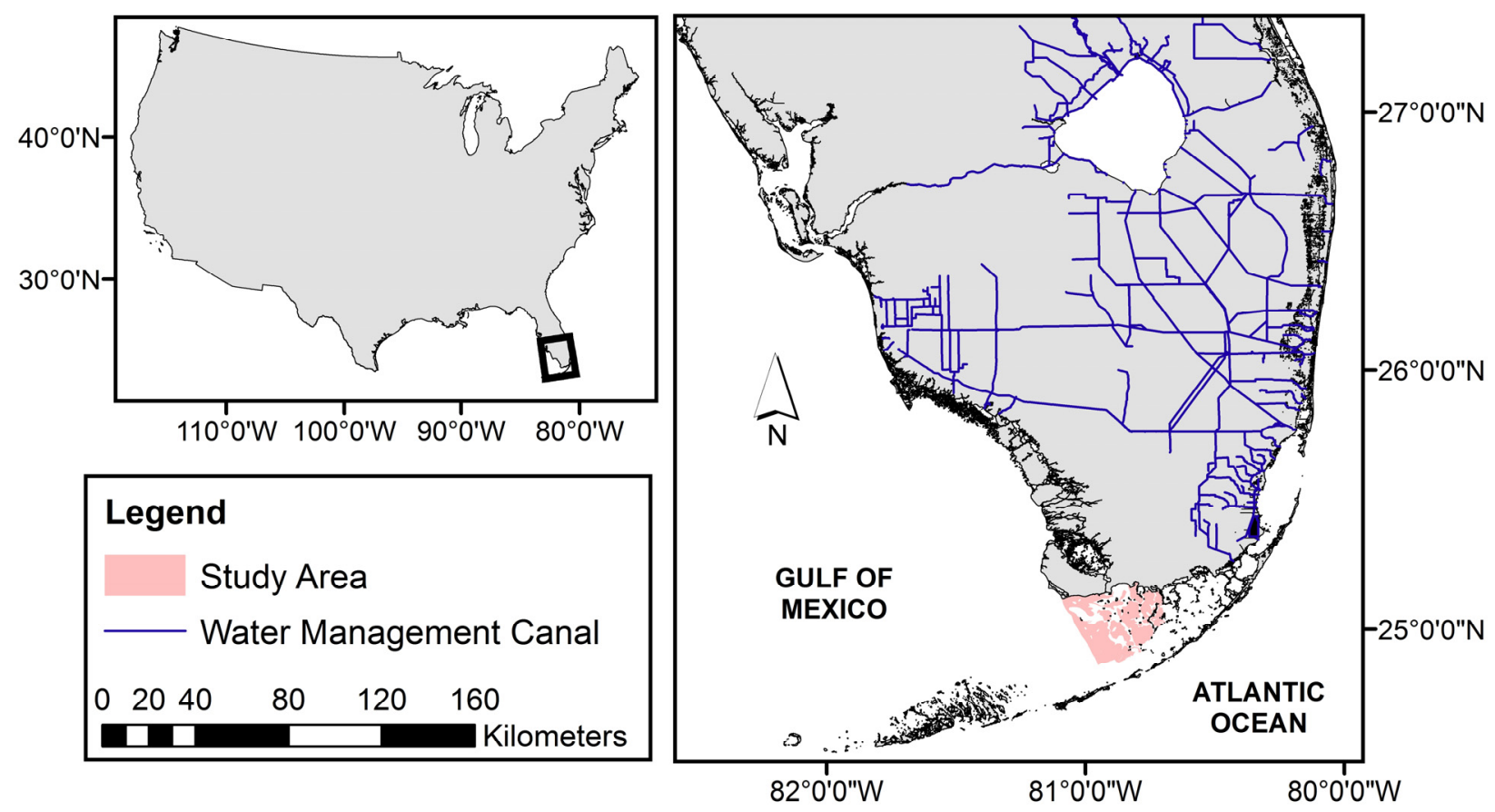

Figure 1. Map showing location of the study area in western Florida Bay, Florida, USA.

The sediments of Florida Bay are mostly composed of biogenic carbonate muds [37] colonized by seagrass beds that occur over $95 \%$ of the bottom of Florida Bay [38]. Thalassia testudinum, turtle grass, is the dominant species in both distribution and biomass and is the climax species in this system [2].

The Florida Bay basins included in this study are located in the north-central and western portions of the lagoon and are alike in their inherent optical water properties, seagrass cover and sediment type [39]. Total attenuation within the water column was found to be significantly correlated to both suspended sediment and chlorophyll-a, but not correlated to colored dissolved organic material within the study area [40]. Delineation of study areas relied on the United States Geological Survey's (USGS) Florida Bay Bottom Types map to identify the bank tops that were omitted from the benthic mapping. Water depth ranges from approximately $1 \mathrm{~m}$ to $4 \mathrm{~m}$ within the study areas, which is illustrated in Figure 2 .

Seagrass communities within the study area are characterized by dense seagrass growth, whereas more eastern Florida Bay communities are dominated by sparse, patchy seagrass cover [39]. The study basins are particularly interesting for seagrass dynamics as a bay-wide investigation into decadal changes in seagrass (1984-1994) found turtle grass decline was not homogeneous throughout the Bay, with the largest reductions in shoot density and biomass occurring in central and western Florida Bay [41]. Statistical analysis of the study area's in-situ seagrass cover data from 1995 to 2012 showed 
seasonal variation to be low and annual variation to be incremental, as would be expected, since tropical seagrass beds are typically stable over the temporal scale of years, even in the advent of severe storms [17].

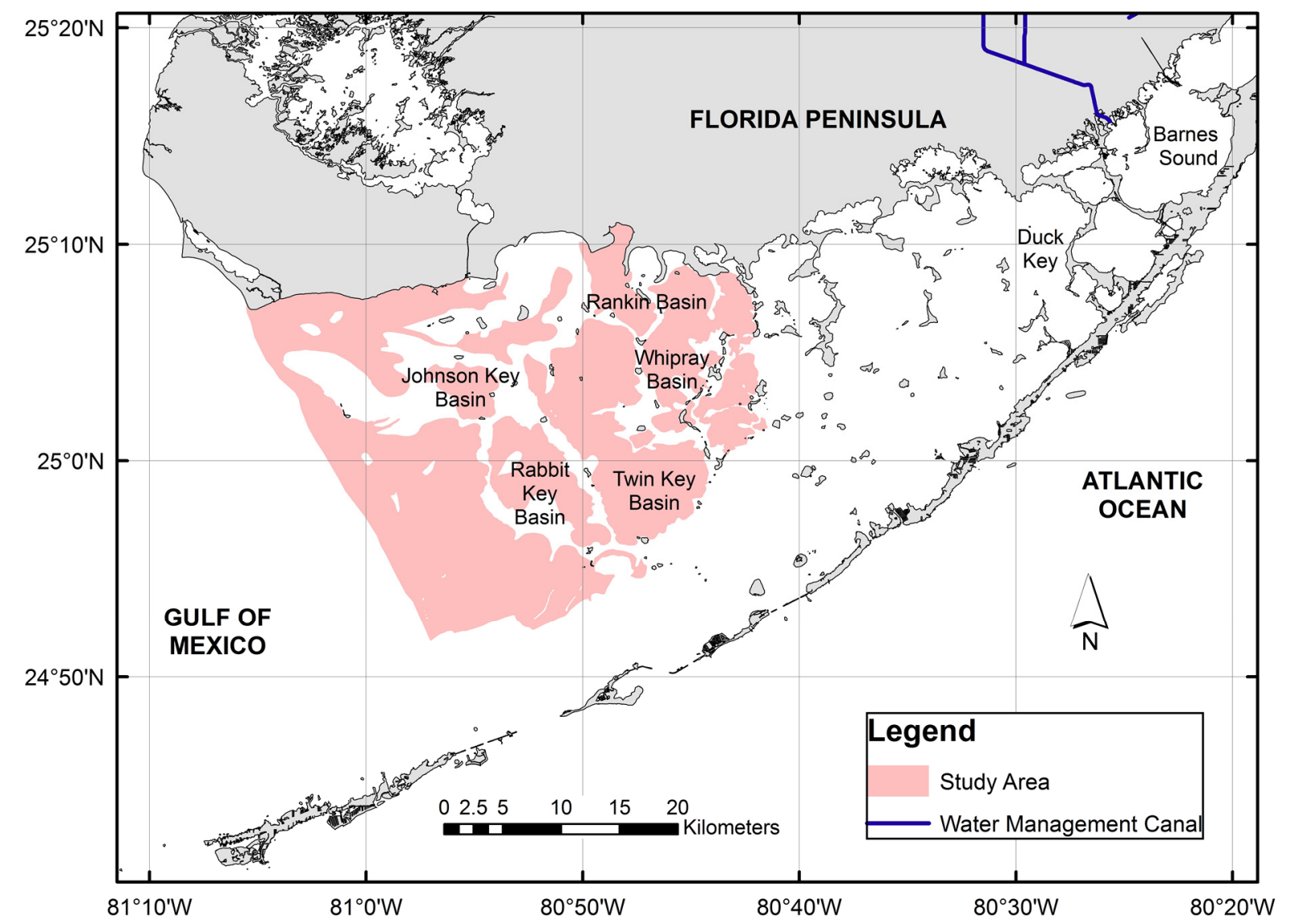

Figure 2. Map overview of Florida Bay and the study area. Field data on seagrass abundance were obtained for labeled basins.

\subsection{Data Sets}

\subsubsection{In-Situ Data}

The Florida Bay Fisheries Habitat Assessment Program (FHAP) was initiated during spring 1995 in response to continuing concerns over environmental changes and seagrass loss within the region. The goal of FHAP is to provide spatially explicit information on the distribution, abundance, species composition, and population dynamics of Florida Bay seagrasses [42]. Sampling for FHAP is conducted during the spring (May-June) at 10 basins representing a range of conditions and gradients in Florida Bay. Five of the FHAP surveyed basins, Johnson Key, Rabbit Key, Twin Key, Whipray, and Rankin, are located within the study area (Figure 2). The basins are partitioned into approximately 30 tessellated, hexagonal grid cells (ranging from 0.5 to $2.6 \mathrm{~km}^{2}$ depending on basin size) for survey purposes, and at every cell seagrass cover is visually quantified within each of four (1995-2004) or eight randomly located $0.25 \mathrm{~m}^{2}$ quadrats using the Braun Blanquet abundance scale [42]. The abundance scale is described in Table 1, where cover is defined as the fraction of the bottom that is obscured by seagrass 
when viewed by a diver from directly above [43]. Whereas seagrass cover data were available for individual seagrass species (Thalassia testudinum, Halodule wrightii, Syringodium filiforme, Ruppia maritime and Halophila engelmanii) from the beginning of the dataset, observations of total seagrass abundance were first recorded in the 2007 dataset. Total seagrass abundance from the 2007-2011 campaigns were employed as ground-truth, reference data in this study.

Table 1. Definition of Braun Blanquet abundance scores used to characterize seagrass cover in-situ.

\begin{tabular}{cc}
\hline Score & Percent Cover \\
\hline 5 & 75 to 100 \\
4 & 50 to 75 \\
3 & 25 to 50 \\
2 & 5 to 25 \\
1 & $<5$ \\
\hline
\end{tabular}

We conducted a preliminary investigation of trends and variability in the FHAP dataset for total seagrass cover prior to employing the survey data for classification purposes. The investigation included a simple graphical analysis of the portion of sites associated with each abundance class and the mean, median and mode class by basin across all available years of data. For the dominant species, Thalassia testudinum, the graphical analysis was also conducted on the full extent of the species-specific FHAP dataset that included seasonal surveys (spring and fall) for the period from 1995 to 2003.

\subsubsection{Satellite Data}

Landsat 5 TM Level-1 data for the study area were obtained from the USGS. One scene, path 15/row 43, covering all study basins was selected for each of the five years (2007-2011) of concurrent FHAP data on total seagrass density. Images of this scene were also retrieved for nine years (1998-2006) for which no total seagrass data were available, to use for qualitative assessment of the classifier. Landsat images were selected to minimize cloud cover and temporal distance from the reference data that were collected in May. The dates of the selected Landsat images with associated in-situ data were 21 April 2007, 7 April 2008, 26 April 2009, 13 April 2010, and 3 June 2011. The dates of selected Landsat images used in the qualitative analysis were 5 May 1998, 3 March 1999, 17 April 2000, 6 May 2001, 18 February 2002, 31 July 2003, 11 March 2004, 15 April 2005, and 4 May 2006. The acquisition time at the sensor was between 10:25 am and 10:45 am (Eastern Time) for all 14 images.

\subsection{Satellite Data Pre-Processing}

Given the relatively low spectral response that reaches remote sensors from underwater subjects [11] and the objective of utilizing the image-based classifier across images, pre-processing of satellite data to adequately correct for atmospheric and water column variation was an important step of this study. The underlying motivation of working towards a mapping methodology that is easily implemented with a minimum of specialized equipment and software influenced the decisions on pre-processing techniques. With the exception of cloud-masking, all pre-processing of the Landsat images, including radiometric calibration, atmospheric correction and water column correction, was completed using ENVI 5.1 image processing software. 
The Fmask (Function of mask) algorithm [44] was used to remove cloud and cloud shadows, as well as land pixels, before atmospheric correction was carried out in ENVI. The Fmask algorithm uses Landsat Top-of-Atmosphere reflectance and Brightness Temperatures as inputs to detect clouds over land and water separately. Geometry-based cloud shadow detection is employed in generation of the shadow layer through use of a flood-fill transformation. The Fmask algorithm separates clouds from shallow or turbid water accurately and can also detect thin clouds and their shadows [44].

Radiometric calibration was carried out in ENVI to convert digital numbers to at-sensor spectral radiance using ENVI's built-in calibration coefficients for the TM sensor.

The Fast Line-of-Sight Atmospheric Analysis of Spectral Hypercubes (FLAASH) module included in ENVI was implemented to translate at-sensor radiance to at-water reflectance. The tropical atmosphere model and maritime aerosol model in FLAASH were selected for the study area. Assessment of the FLAASH atmospheric correction code under a similar parameterization of the module and using in-situ spectral samples was performed in a previous study in western Florida, which found spectra extracted from the atmospherically corrected Landsat data to show an approximately consistent tendency of spectral variation when compared with the in-situ samples [17]. Aerosol and water vapor retrieval options were not activated for the current study. The historical meteorological data corresponding with each of the Landsat scenes did not support changing the modeled atmospheric conditions across the various years.

Detection of seagrasses and other benthic environments is complicated by the fact that they are covered by a water column that attenuates the light reaching, interacting with, and being reflected from the benthos. As attenuation is a function of the depth of the overlying water column, a correction for water column depth was performed prior to classification. Because of the relative ease of implementation and proven effectiveness [45-47], Lyzenga's method for creating depth-invariant bands [48,49] was implemented.

Lyzenga's method assumes that light attenuation follows an exponential decay curve with increasing depth, which is often satisfied for tropical coastal waters [47]. Although the ratios of the water attenuation coefficients for the wavelength bands used are required as input for the water column depth correction, these parameters can be obtained from the Landsat images as long as pixels representing a uniform substrate but variable depth can be identified, given differences in reflectance between different pixels of the same substrate are attributable entirely to differences in depth. Bare mud pixels varying from approximately $1 \mathrm{~m}$ to $4 \mathrm{~m}$ in depth were selected from the calibration images based on the Florida Bay Bottom Types map, bathymetric contours produced by the USGS, and visual interpretation of the imagery. Three ratios of attenuation, between wavelength bands $1(0.45-0.52 \mu \mathrm{m})$ and $2(0.52-0.60 \mu \mathrm{m})$, bands 1 and $3(0.63-0.69 \mu \mathrm{m})$, and bands 2 and 3 were calculated. Comparison of the ratios derived for this study with the measured downwelling attenuation coefficient showed the derived ratios to be reasonable, lying between those measured in-situ immediately west of Florida Bay and in the Caribbean Sea (where a spectral shape typical for oligotrophic Case I waters was measured) [50]. All three depth-invariant bands produced based on the calculated ratios of attenuation were then used for the benthic classification.

\subsection{Seagrass Classification}

The Landsat scenes from the years 2009 to 2011 were used for calibration of the classifier (training pixel selection), and 2007 and 2008 were used for validation purposes. This segregation of the in-situ data represented the scenario where field data are collected to retrospectively map a time series of seagrass 
density and allows evaluation of the transferability of the pixel-based classifier to older images. Every pixel containing a field sampling station from the 2009 to 2011 calibration set that was not identified as cloud or land was employed in training the classifier. For the validation pixels, sampling site pixels identified as cloud or land or classified as turbid were omitted from accuracy assessment calculations.

As seagrass percent cover often varies at a spatial scale of $<1 \mathrm{~m}$ [30], using a single pixel instead of a neighborhood average was deemed appropriate. The FHAP field data record the Braun Blanquet abundance class at four quadrats making up each survey site. The average abundance score for each field site was calculated as the mean of the quadrat scores and then used to group the field sites into four classes, as shown in Table 2. The sparse cover class was defined to represent areas that are predominantly bare sediment. Specification of low and dense classes was based on typical definitions for these classes from the literature [13-17]. Spectral evaluation of the four reference classes revealed that medium and dense training pixels were difficult to distinguish from one another, so they were merged to define a single medium-dense spectral class. Turbid water areas, evidenced by visual interpretation of the calibration scenes and preliminary unsupervised K-means classification, were sampled to define a fourth class.

Table 2. Summary of seagrass cover classes employed in this study, including the number of pixels used for training and validation. Pixels representing medium and dense seagrass cover were grouped for selection of training pixels.

\begin{tabular}{|c|c|c|c|c|c|c|}
\hline \multirow{2}{*}{ Class } & \multirow{2}{*}{$\begin{array}{c}\text { Avg. Braun-Blanquet } \\
\text { Score } \\
\end{array}$} & \multicolumn{3}{|c|}{ Training Samples (Pixels) } & \multicolumn{2}{|c|}{ Validation Samples (Pixels) } \\
\hline & & 2009 & 2010 & 2011 & 2007 & 2008 \\
\hline Dense & $>4.5$ & \multirow{2}{*}{82} & \multirow{2}{*}{104} & \multirow{2}{*}{98} & 15 & 10 \\
\hline Medium & 2.5 to 4.5 & & & & 74 & 76 \\
\hline Low & 1.5 to 2.5 & 25 & 13 & 26 & 19 & 40 \\
\hline Sparse & $<1.5$ & 4 & 5 & 5 & 20 & 8 \\
\hline
\end{tabular}

\subsection{Error Matrix and Accuracy Assessment}

Seagrass maps were produced based on the three depth-invariant bands for each year, and statistics on the spectral classes (from training pixels spanning years 2009 to 2011) using ENVI's Maximum Likelihood classifier with no probability threshold and a data scale factor of 1 . The Maximum Likelihood classification method is based on the Bayes' theorem, with class mean vector and covariance matrix input to a discriminant function to assign pixels to the class with the highest likelihood [51]. The geo-referenced field data corresponding to the 2007 and 2008 images, which were not included in the calibration, were used as reference pixels to derive the error matrix and calculate the producer's, user's and overall accuracies of the classifier. The error matrix displays the proportion of all mapped pixels that are of map class $i$ and reference class $j$ (pij), where the diagonals of the matrix represent correctly classified areas and off-diagonals identify classification errors. Row margins (pi+) are the proportion of pixels classified as class $i$ and column margins $(p+j)$ estimate the proportion of area of class $j$. Table $3[52,53]$ shows the producer's, user's and overall accuracies of our resulting classification.

To further examine the validity of the study methodology, Landsat 5 images from 1998 to 2006 were classified. Only the interior basins that are less affected by waves were included in this mapping exercise. Although no in-situ survey data on total seagrass cover were available for the 1998-2006 maps, the 
extended temporal span enables a qualitative assessment of the applicability of the methodology to time series data through evaluation of the longer term changes depicted by the map products.

Table 3. Seagrass cover classification error matrix and accuracy assessment measures for each validation scene.

\begin{tabular}{|c|c|c|c|c|c|c|c|c|}
\hline & & & \multicolumn{6}{|c|}{ Reference Class } \\
\hline & & & Dense & Medium & Low & Sparse & Total & ** Users Accuracy \\
\hline \multirow{10}{*}{$\begin{array}{l}\text { Map } \\
\text { Class }\end{array}$} & & Med-Dense & $9 \%$ & $48 \%$ & $5 \%$ & $0 \%$ & $63 \%$ & $93 \%$ \\
\hline & & Low & $2 \%$ & $8 \%$ & $6 \%$ & $4 \%$ & $20 \%$ & $31 \%$ \\
\hline & 2007 & Sparse & $0 \%$ & $2 \%$ & $4 \%$ & $12 \%$ & $17 \%$ & $68 \%$ \\
\hline & & Total & $12 \%$ & $58 \%$ & $4 \%$ & $16 \%$ & \multirow{2}{*}{\multicolumn{2}{|c|}{$* * *$ Overall Accuracy $=76 \%$}} \\
\hline & & * Producers Accuracy & $80 \%$ & $84 \%$ & $42 \%$ & $75 \%$ & & \\
\hline & \multirow{5}{*}{2008} & Med-Dense & $7 \%$ & $51 \%$ & $8 \%$ & $0 \%$ & $66 \%$ & $88 \%$ \\
\hline & & Low & $0 \%$ & $4 \%$ & $4 \%$ & $1 \%$ & $8 \%$ & $45 \%$ \\
\hline & & Sparse & $0 \%$ & $2 \%$ & $18 \%$ & $5 \%$ & $25 \%$ & $21 \%$ \\
\hline & & Total & $7 \%$ & $57 \%$ & $30 \%$ & $6 \%$ & \multirow{2}{*}{\multicolumn{2}{|c|}{ Overall Accuracy $=67 \%$}} \\
\hline & & Producers Accuracy & $100 \%$ & $89 \%$ & $13 \%$ & $88 \%$ & & \\
\hline
\end{tabular}

\footnotetext{
* Producer's accuracy, a measure of the error of omission for each class, is the proportion of correctly mapped pixels for a given class in the reference data. ** User's accuracy, a c measure of the error of commission, is the proportion of pixels incorrectly identified as belonging to a given class. $* * *$ Overall accuracy measures agreement at the map level, as opposed to the category level, where overall accuracy is the sum of the error matrix diagonals. For more detail on accuracy measures, the reader is directed to Liu et al. [52] and Olofsson et al. [53].
}

\section{Results and Discussion}

The classified maps produced in this study showed general agreement with the trends indicated by the point data from the in-situ surveys. Assessment of the changes in seagrass cover suggests that interior basins were classified more accurately than the portions of the study area adjacent to the Gulf of Mexico.

\subsection{In-Situ Data Description and Distribution}

Evaluation of the in-situ dataset of seagrass cover collected by the FHAP indicated there were temporal trends in seagrass distribution that varied with space throughout the study area. Although the seagrass dataset also included fall cover surveys for years from 1995 to 2003 (whereas spring surveys were conducted over the program's entire duration until 2012), no pattern of seasonal variability was discerned within any of the study area survey basins.

Total seagrass cover from 2007 to 2012 showed mean cover remaining relatively stable from year to year within each basin over the five most recent years. Mean total seagrass cover increased toward the west within the surveyed study area basins, as shown in the plots of in-situ survey data in Figure 3. The median and mode of total seagrass cover also generally increased to the west. The in-situ points suggested annual variability in seagrass abundance illustrated by changes in the location of the transition from low to medium-dense cover each year. 

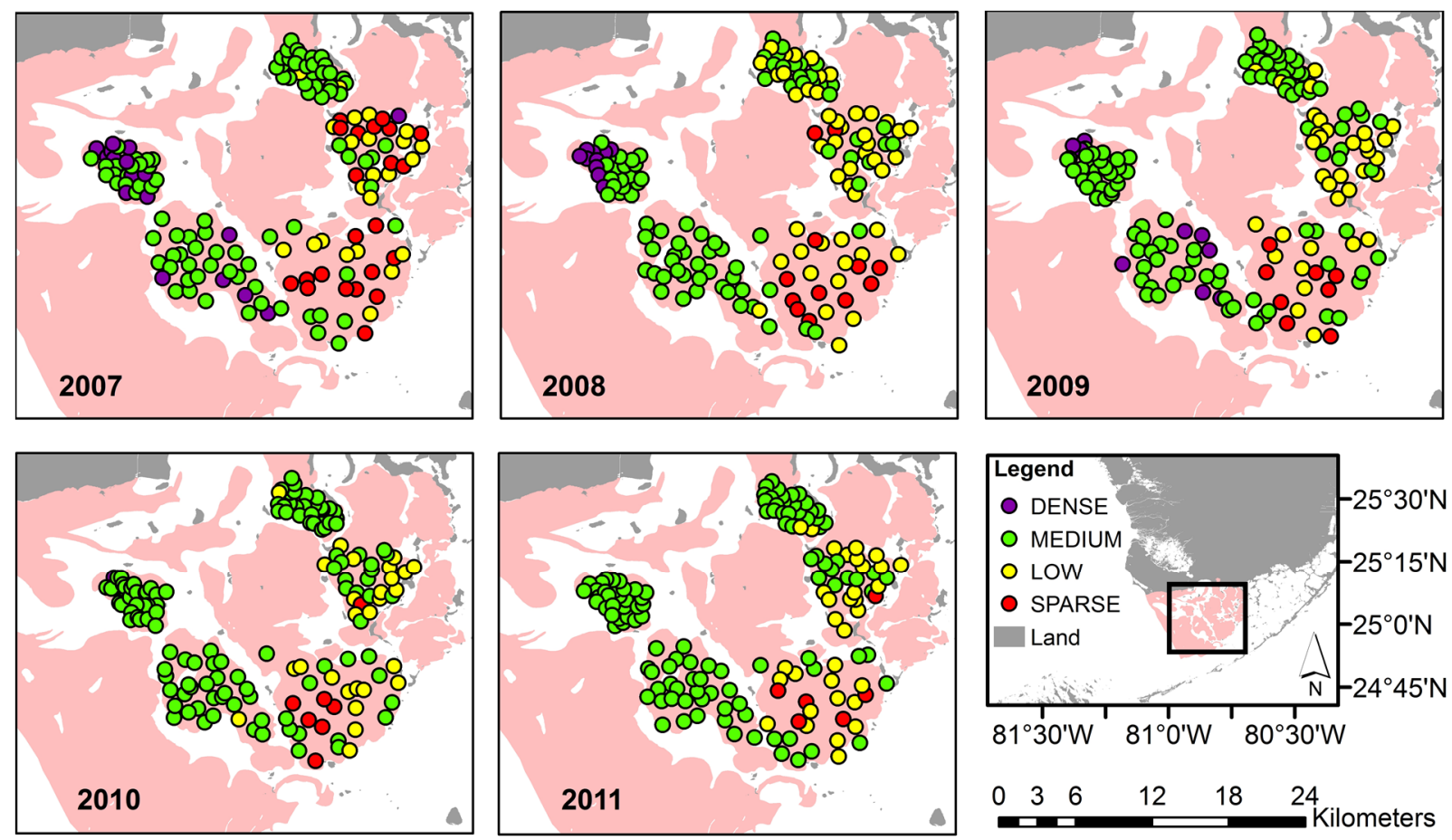

Figure 3. Map summary of in-situ data showing the distribution of cover classes across survey sites.

Observation of species-specific seagrass abundance from early in the FHAP survey (before total seagrass cover was recorded) showed greater inter-annual variability over the period from 1995 to the early 2000's than in more recent years. Since 1995, Thalassia testudinum showed an increasing trend in the northern FHAP basins included in the study area and a more stable or possibly decreasing cover trend to the south.

\subsection{Image Classification}

The overall accuracy for each validation year of $67 \%$ in 2007 and $76 \%$ in 2008 was within the range of accuracies achieved from other studies employing supervised classification of Landsat data to map seagrass $[16,17,30]$. Substantial differences in the classification accuracy by cover class are apparent, with the Low cover class performing the worst and all other cover classes exceeding $75 \%$ producer's accuracy in either validation year (Table 3). Because seagrasses have been observed to be patchier at lower standing crop [12], the poor producer's accuracy of the low cover class may be caused by high intra-pixel variation for pixels exhibiting areas of low cover.

From visual interpretation, the arrangement of cover classes in the map products for the validation years appear to match the patterns represented in the in-situ data (Figure 4). The portions of the study area providing the most interesting indicators of classification accuracy are the two easternmost basins, which included a more heterogeneous mix of cover classes in the ground truth data. Although these heterogeneous areas perform worse in terms of matching the field data class to the class assigned to the corresponding pixel, misclassified pixels tend to be located along the transitions between larger groups of different cover classes or in areas where the reference class is only present in small patches within a more dominant cover class according to the map product. These observations suggest that some of the 
classification error may result from the difference in the spatial scale of the in-situ observation and satellite pixel.
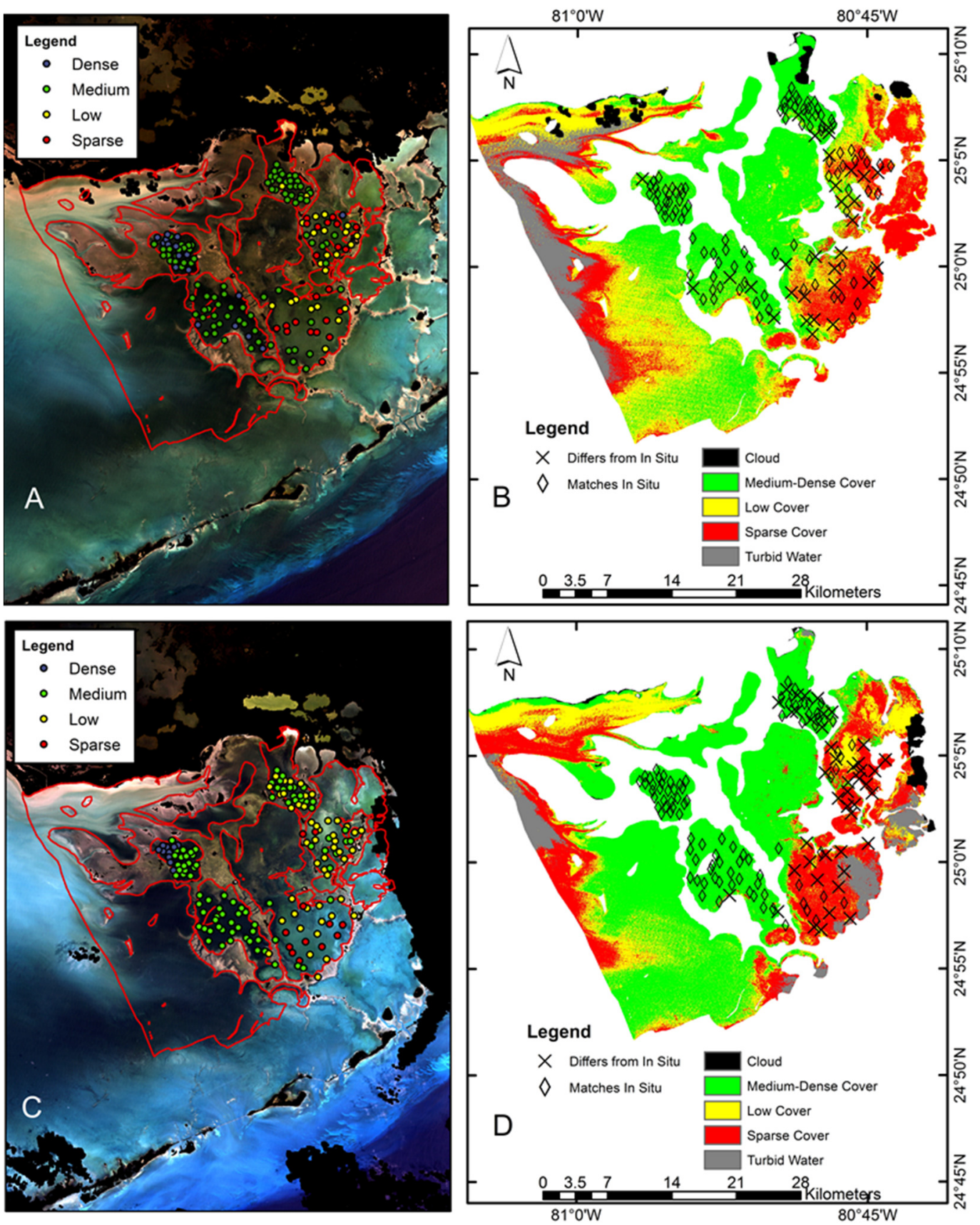

Figure 4. (A) 2007 true color composite of the study area showing in-situ data; (B) 2007 seagrass cover mapping product showing coherence with in-situ data; (C) 2008 true color composite of study area showing in-situ data; (D) 2008 seagrass cover mapping product showing coherence with in-situ data.

The discrepancy between the spatial domain represented by a single Landsat pixel (30 $\mathrm{m}$ by $30 \mathrm{~m})$ and in-situ reference site $(0.5 \mathrm{~m}$ by $0.5 \mathrm{~m})$ remained a substantial source of uncertainty for both classifier calibration and accuracy assessment. For example, very few field survey sites were classified as having dense cover each year and no dense field sites were observed in calibration year 2011 . Therefore, it may 
be unrealistic for the much larger Landsat pixels to have dense cover throughout even though some pixels were classified as dense based on the field sample contained by those pixels. In other words, the field sample may not accurately represent the more expansive Landsat pixel so that actual classification accuracy may be higher than those reported in Table 3.

Another evaluation of the classification accuracy was to determine whether the trends and variability expressed through the map products were reasonable. The interior regions did not show much change in seagrass cover, but the easternmost basins indicated seagrass loss between 2007 and 2008 and an apparent westward retreat of the transition zone from dense to sparse cover (see also Figure 5). The location and timing of the change in seagrass indicated by the 2007 and 2008 maps may be attributed to an algal bloom in the eastern portions of Florida Bay. The algal bloom began in fall of 2005 within the vicinity of Barnes Sound and extended along eastern Florida Bay to Duck Key by November 2005 [54]. The northeastern algal bloom reoccurred seasonally in 2006 and 2007, extending to north-central portions of the Bay in 2007 and subsiding by May 2008 [54]. It is reasonable to surmise that seagrass cover was reduced in areas adjacent to the persistent algal bloom.

The portions of the study area immediately adjacent to the Gulf of Mexico show a westward expansion of dense seagrass in the 2007 and 2008 map products, as well as a reduction in turbid water area, from 2007 to 2008. In these western portions of the bay, which are more influenced by tides and waves than are the interior portions of the study area, the classifier may be categorizing turbid water as low and sparse seagrass. Although it is difficult to determine without corresponding field data whether the Gulf-adjacent areas are misclassified, the classifier may be inappropriate for these portions of the bay.

Figure 5 presents the results of applying the classifier to the interior portions of the study area over an extended time series back to 1998. The inter-annual variability illustrated by the map products shown in Figure 5 is consistent with the observed trends in the dominant Thalassia testudinum's FHAP survey data from the 1998 to 2006. An increasing trend in T. testudinum's cover class data is indicated in Johnson Key and Rankin basins over the 1998 to 2008 period while an increasing trend persisted in Rabbit Key Basin from 1998 to the mid-2000s. The Thalassia cover data show a steady or somewhat decreasing trend in Twin Key Basin, though no trend is apparent in Whipray Basin over the 1998-2008 period.

A more statistically thorough investigation into the FHAP survey data, conducted by Landry in 2005 [55] on the data available up to that point (1995-2004) also corroborates the inter-annual variability indicated by the Figure 5 map products. For example, Landry found that for Rankin Basin, Halodule densities, which were generally denser in north and eastern portions of the basin, dominated until 2002 when Thalassia, which was denser in the south part of the basin, surpassed Halodule. Additionally, Landry found Thalassia to be generally denser around the perimeter and western area of Twin Key basin, that Thalassia is much denser in the eastern portions of Rabbit Key basin than in western portions, and that Rabbit Key Thalassia densities rebound and then level off over the 1998 to 2004 period.

Although Figure 5 shows that turbidity is still an issue in multiple years even in the interior basins, the proximity of areas classified as turbid and medium-dense in 1999 suggests that the remainder of the map product (i.e., area not classified as turbid) is valid for the purposes of landscape scale monitoring of the benthic environment. 

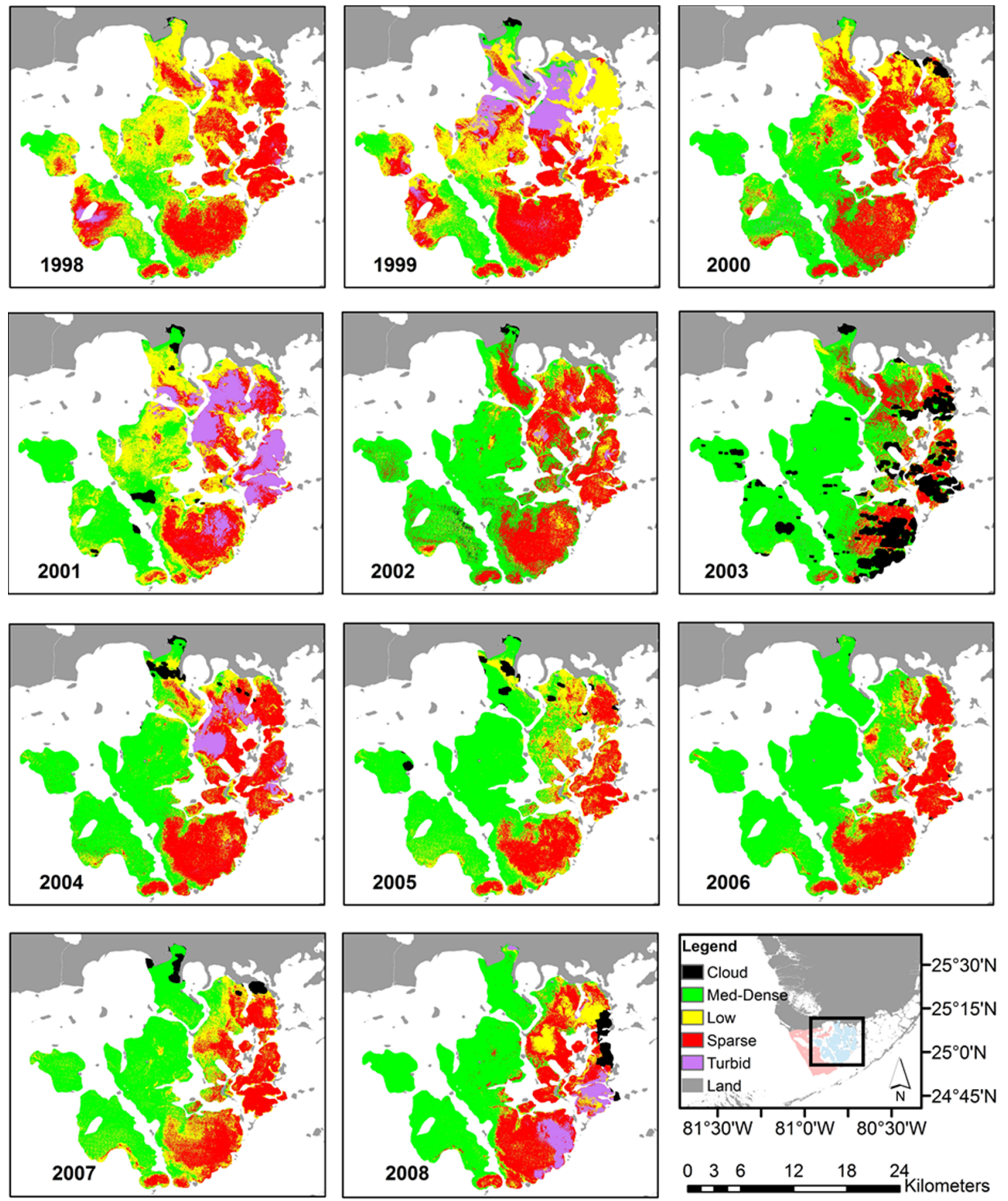

Figure 5. Seagrass cover mapping products for 1998 to 2008.

One caution with our methodology is that the water column optical properties must be similar for all pixels within a study area and across the various scenes evaluated. We minimized variation in water column components across scenes in this study by using data from the same season each year. In addition, turbidity was minimized since the study scenes occurred toward the end of the dry season.

\section{Conclusions}

This study demonstrated that a pixel-based classifier trained on data compiled using Landsat 5 images from three consecutive years was extendible to time-series images from an earlier period for the same study area. Although spectral library methods may be preferred in terms of transferability across images, 
the classification accuracies achieved in this study (76\% and $67 \%$ overall accuracy, but $75 \%$ to $100 \%$ accuracy for three of four classes in the two validation images) showed that meaningful information could be obtained through simpler techniques.

Although there are limitations to the methodology employed in this study, the importance of understanding valuable and dynamic coastal systems warrants the use of methodologies that allow greater interpretation of available synoptic data. Estimating the status of valuable coastal marine habitats provides better evidence for environmental changes and aids in the description of the processes that are behind the changes [28]. For example, the patchy mortality characteristic of seagrass die-off is very different from the gradual thinning and loss of seagrasses due to decreased water clarity [41]. Despite these benefits, the potential for using remote sensing to monitor environmental factors influencing seagrass loss has, thus far, been little explored [8]. Our assessment suggests that pixel-based classifiers of benthic habitats developed for specific images can be generalized and extended to images from other years, expediting the time series mapping that is required to adequately inform coastal resource management.

As reflectances from benthic environments and the water column are integrated in remotely sensed images of shallow, relatively clear coastal waters, maps of benthic properties which can be assumed stable over some period of time are also helpful in interpreting satellite data for information on water column properties. For example, if the benthic cover can be assumed fixed over a season or longer variations in reflectance may be attributed to changes in water column properties. Remote sensing products that accurately detect transient water column properties, particularly chlorophyll-a which is indicative of algal blooms, can then be used to improve the environmental conditions affecting coastal ecosystems.

Because a common radiometric scale is assumed across all images in a time series mapped with a single classifier, atmospheric correction is an important consideration for the studied methodology. Atmospheric correction procedures derived specifically for normalizing surface reflectances across images, although likely to improve the transferability of pixel-based classifiers, were not employed in this study and should be evaluated in future work.

The accessibility of our method, in terms of equipment, software and expertise required, promotes the use of the Landsat archive for multi-temporal analyses of coastal dynamics. Future field data collection efforts for application to benthic habitat mapping are recommended to consider the remote sensor's spatial resolution during survey design. The ability to identify the benthic characteristics for an entire pixel from field data would improve the precision of both classifier training and accuracy assessment, potentially increasing the utility of the resulting map products to researchers and managers.

\section{Acknowledgments}

This study was funded by the NASA WaterSCAPES Project and the Florida Education Fund's McKnight Fellowship program. The authors would like to thank the Florida Fish and Wildlife Conservation Commission, which collected and provided the in-situ data for this study.

\section{Author Contributions}

Tara Blakey was the primary analyst and author for this work. Assefa Melesse was the corresponding author and contributed as a supervisor to the research and writing of the paper. Margaret Hall contributed to the research and writing as an expert on the in situ dataset. 


\section{Conflicts of Interest}

The authors declare no conflicts of interest.

\section{References}

1. Koch, M.S.; Schopmeye, S.; Holmer, M.; Madden, C.; Kyn-Hansen, C. Thalassia testudinum response to the interactive stressors hypersalinity, sulfide and hypoxia. Aquat. Bot. 2007, 87, 104-110.

2. Madden, C.J.; Rudnick, D.T.; McDonald, A.A.; Cunniff, K.M.; Fourqurean, J.W. Ecological indicators for assessing and communicating seagrass status and trends in Florida Bay. Ecol. Indic. 2009, 9, S68-S82.

3. Yaakub, S.M.; Chen, E.; Bouma, T.; Erftemeijer, P.; Todd, P. Chronic light reduction reduces overall resilience to additional shading stress in the seagrass Halophila ovalis. Mar. Pollut. Bull. 2013, 83, 467-474.

4. Fourqurean, J.W.; Duarte, C.; Kennedy, H.; Marba, N.; Holmer, M.; Mateo, M.; Apostolaki, E.; Kendrick, G.; Krause-Jensen, D.; McGlathery, K.; et al. Seagrass ecosystems as a globally significant carbon stock. Nat. Geosci. 2012, 5, 505-509.

5. Fourqurean, J.W.; Kendrick, G.A.; Collins, L.S.; Chambers, R.M.; Vanderklift, M.A. Carbon, nitrogen and phosphorous storage in subtropical seagrass meadows: Examples from Florida Bay and Shark Bay. Mar. Freshw. Res. 2012, 63, 967-983.

6. Collier, C.J.; Waycott, M.; Ospina, A. Responses of four Indo-West Pacific seagrass species to shading. Mar. Pollut. Bull. 2012, 65, 342-354.

7. Hill, V.J.; Zimmerman, R.; Bissett, W.; Dierssen, H.; Kohler, D. Evaluating light availability, seagrass biomass, and productivity using hyperspectral airborne remote sensing in Saint Joseph's Bay, Florida. Estuaries Coasts 2014, 37, 1467-1489.

8. Ferweda, J.; de Leeuw, J.; Atzberger, C.; Vekerdy, Z. Satellite-based monitoring of tropical seagrass vegetation: Current techniques and future developments. Hydrobiologia 2007, 591, 59-71.

9. Thorhaug, A.; Richardson, A.; Berlyn, G. Spectral reflectance of Thalassia testudinum (Hydrocharitaceae) seagrass: Low salinity effects. Am. J. Bot. 2006, 93, 110-117.

10. Yaakub, S.M.; McKenzie, L.; Erftemeijer, P.; Bouma, T.; Todd, P. Courage under fire: Seagrass persistence adjacent to a highly urbanized city-state. Mar. Pollut. Bull. 2014, 83, 417-424.

11. Dekker, A.; Brando, V.; Anstee, J.; Fyfe, S.; Malthus, T.; Karpouzli, E. Remote sensing of seagrass ecosystems: Use of spaceborne and airborne sensors. In Seagrass: Biology, Ecology, and Conservation; Springer: Dordrecht, The Netherlands, 2006; Chapter 15, pp. 347-359.

12. Mumby, P.J.; Green, E.P.; Edwards, A.J.; Clark, C.D. Measurement of seagrass standing crop using satellite and digital airborne remote sensing. Mar. Ecol. Prog. Ser. 1997, 159, 51-60.

13. Lyons, M.B.; Phinn, S.R.; Roelfsema, C.M. Long term land cover and seagrass mapping using Landsat and object-based image analysis from 1972 to 2010 in the coastal environment of South East Queensland, Australia. ISPRS J. Photogramm. Remote Sens. 2012, 71, 34-46. 
14. Phinn, S.; Roelfsema, C.; Dekker, A.; Brando, V.; Anstee, J. Mapping seagrass species, cover and biomass in shallow waters: An assessment of satellite mutli-spectral and airborne hyperspectral imaging systems in Moreton Bay (Australia). Remote Sens. Environ. 2008, 112, 3413-3425.

15. Roelfsema, C.M.; Phinn, S.R.; Udy, N.; Maxwell, P. An integrated field and remote sensing approach for mapping seagrass cover, Moreton Bay, Australia. Spat. Sci. 2009, 54, 45-62.

16. Wabnitz, C.C.; Andrefouet, S.; Torres-Pulliza, D.; Muller-Karger, F.E.; Kramer, P.A. Regional scale seagrass habitat mapping in the Wider Caribbean region using Landsat sensors: Applications to conservation and ecology. Remote Sens. Environ. 2008, 112, 3455-3467.

17. Pu, R.; Bell, S.; Meyer, C.; Baggett, L.; Zhao, Y. Mapping and assessing seagrass along the western coast of Florida using Landsat TM and EO-1 ALI/Hyperion imagery. Estuar. Coast. Shelf Sci. 2012, $115,234-245$.

18. Kim, K.; Choi, J.; Ryu, J.; Jeong, H.J.; Lee, K.; Park, M.G.; Kim, K.Y. Observation of typhoon-induced seagrass die-off using remote sensing. Estuar. Coast. Shelf Sci. 2015, 154, 111-121.

19. Pu, R.; Bell, S.; Meyer, C. Mapping and assessing seagrass bed changes in Central Florida's west coast using multitemporal Landsat TM imagery. Estuar. Coast. Shelf Sci. 2014, 149, 68-79.

20. Roelfsema, C.; Kovacs, E.; Saunders, M.I.; Phinn, S.; Lyons, M.; Maxwell, P. Challenges of remote sensing for quantifying changes in large complex seagrass environments. Estuar. Coast. Shelf Sci. 2013, 133, 161-171.

21. Kutser, T.; Miller, I.; Jupp, D. Mapping coral reef benthic substrates using hyperspectral space-borne images and spectral libraries. Estuar. Coast. Shelf Sci. 2006, 70, 449-460.

22. Dekker, A.G.; Brando, V.E.; Anstee, J.M. Retrospective change detection in a shallow coastal tidal Australian lake. Remote Sens. Environ. 2005, 97, 415-433.

23. Louchard, E.M.; Reid, P.; Stephens, F.; Davis, C.; Leathers, R.; Downes, V. Optical remote sensing of benthic habitats and bathymetry in coastal environments at Lee Stocking Island, Bahamas: A comparative spectral classification approach. Limnol. Oceanogr. 2003, 48, 511-521.

24. Wolf, P.; Robler, S.; Schneider, T.; Melzer, A. Collecting in situ remote sensing reflectances of submersed macrophytes to build up a spectral for lake monitoring. Eur. J. Remote Sens. 2013, 46, 401-416.

25. Dierssen, H.M.; Zimmerman, R.C.; Drake, L.A.; Burdige, D. Benthic ecology from space: Optics and net primary production in seagrass and benthic algae across the Great Bahama Bank. Mar. Ecol. Prog. Ser. 2010, 411, 1-15.

26. Kutser, T.; Vahtmae, E.; Metsamaa, L. Spectral library of macroalgae and benthic substrates in Estonian coastal waters. Proc. Est. Acad. Sci. Biol. Ecol. 2006, 55, 329-340.

27. Dierssen, H.; Zimmerman, R.C.; Leathers, R.A.; Downes, T.V.; Davis, C.O. Ocean color remote sensing of seagrass and bathymetry in the Bahamas Banks by high-resolution airborne imagery. Limnol. Oceanogr. 2003, 48, 444-455.

28. Vahtmae, E.; Kutser, T. Classifying the Baltic Sea shallow water habitats using image-based and spectral library methods. Remote Sens. 2013, 5, 2451-2474.

29. Zomer, R.J.; Trabucco, A.; Ustin, S. Building spectral libraries for wetlands land cover classification and hyperspectral remote sensing. J. Environ. Manag. 2009, 90, 2170-2177. 
30. Lyons, M.B.; Roelfsema, C.M.; Phinn, S.R. Towards understanding temporal and spatial dynamics of seagrass landscapes using time-series remote sensing. Estuar. Coast. Shelf Sci. 2012, 120, 42-53.

31. Hossain, M.S.; Bujang, J.S.; Zakaria, M.H.; Hashim, M. The application of remote sensing to seagrass ecosystems: An overview and future prospects. Int. J. Remote Sens. 2015, 36, 61-114.

32. Barnes, B.B.; Hu, C.; Holekamp, K.; Blonski, S.; Spiering, B.; Palandro, D.; Lapointe, B. Use of Landsat data to track historical water quality changes in Keys marine environments. Remote Sens. Environ. 2014, 140, 485-496.

33. McPherson, M.L.; Hill, V.J.; Zimmerman, R.C.; Dierssen, H.M. The optical properties of Greater Florida Bay: Implications for seagrass abundance. Estuar. Coasts 2011, 34, 1150-1160.

34. Nagel, J.L.; Kemp, W.M.; Cornwell, J.C.; Owens, M.S.; Hinkle, D.; Madden, C.J. Seasonal and regional variations in net ecosystem production in Thalassia testudinum communities throughout Florida Bay. Contrib. Mar. Sci. 2009, 38, 91-108.

35. Lee, T.; Williams, E.; Johns, E.; Wilson, D.; Smith, N.P. Transport processes linking south Florida coastal systems. In The Evergades, Florida Bay and Coral Reefs of the Florida Keys: An Ecosystem Sourcebook; CRC Press: Boca Raton, FL, USA, 2002; pp. 309-341.

36. Lee, T.; Smith, N. Volume transport variability through the Florida Keys tidal channels. Cont. Shelf Res. 2002, 22, 1361-1377.

37. Taylor, K.H.; Purkis, S.J. Evidence for the southward migration of mud banks in Florida Bay. Mar. Geol. 2012, 311, 52-56.

38. Boyer, J.N.; Fourqurean, J.W.; Jones, R.D. Spatial characterization of water quality in Florida Bay and Whitewater Bay by multivariate analyses: Zones of similar influence. Estuaries 1997, 4, 743-758.

39. Zieman, J.C.; Fourqurean, J.W.; Iverson, R.L. Distribution, abundance and productivity of seagrasses and macroalgae in Florida Bay. Bull. Mar. Sci. 1989, 441, 292-311.

40. Phlips, E.J.; Lynch, T.C.; Badylak, S. Chlorophyll a, tripton, color, and light availability in a shallow tropical inner-shelf lagoon, Florida Bay, USA. Mar. Ecol. Prog. Ser. 1995, 127, 223-234.

41. Hall, M.O.; Durako, M.J.; Fourqurean, J.W.; Zieman, J.C. Decadal changes in seagrass distribution and abundance in Florida Bay. Estuaries 1999, 22, 445-459.

42. Hall, M.; Madley, K.; Durako, M.; Zieman, J.; Robblee, M. Florida Bay. Seagrass Status and Trends in the Northern Gulf of Mexico: 1940-2002; Scientific Investigations Report 2006-5287; U.S. Geologic Survey: Reston, VA, USA, 2007; pp. 242-252.

43. Fourqurean, J.W.; Durako, M.; Hall, M.; Hefty, L. Seagrass distribution in South Florida: A multi-agency coordinated monitoring program. In The Evergades, Florida Bay and Coral Reefs of the Florida Keys: An Ecosystem Sourcebook; CRC Press: Boca Raton, FL, USA, 2002; pp. 497-522.

44. Zhu, Z.; Woodcock, C.E. Object-based cloud and shadow detection in Landsat imagery. Remote Sens. Environ. 2012, 118, 83-94.

45. Zoffoli, M.L.; Frouin, R.; Kampel, M. Water column correction for coral reef studies by remote sensing. Sensors 2014, 14, 16881-16931.

46. Amran, M.A. Estimation of seagrass coverage by depth invariant indices on quickbird imagery. Biotropia 2010, 17, 42-50. 
47. Mumby, P.J.; Clark, C.D.; Green, E.P.; Edwards, A.J. Benefits of water column correction and contextual editing for mapping coral reefs. Int. J. Remote Sens. 1998, 19, 203-210.

48. Lyzenga, D.R. Passive remote sensing techniques for mapping water depth and bottom features. Appl. Opt. 1978, 17, 379-383.

49. Lyzenga, D.R. Remote sensing of bottom reflectance and water attenuation parameters in shallow water using aircraft and Landsat data. Int. J. Remote Sens. 1981, 2, 71-82.

50. Zhao, J.; Barnes, B.; Melo, N.; English, D.; Lapointe, B.; Muller-Karger, F.; Schaeffer, B.; Hu, C. Assessment of satellite-derived diffuse attenuation coefficients and euphotic depths in south Florida coastal waters. Remote Sens. Environ. 2013, 131, 38-50.

51. Ahmad, A.; Quegan, S. Analysis of Maximum Likelihood classification on multispectral data. Appl. Math. Sci. 2012, 6, 6425-6436.

52. Liu, C.; Frazier, P.; Kumar, L. Comparative assessment of the measures of thematic classification accuracy. Remote Sens. Environ. 2007, 107, 606-616.

53. Olofsson, P.; Foody, G.M.; Herold, M.; Stehman, S.V.; Woodcock, C.E.; Wulder, M.A. Good practice for estimating area and assessing the accuracy of land change. Remote Sens. Environ. 2014, 148, 42-57.

54. Restoration Coordination and Verification (RECOVER). 2009 System Status Report. Comprehensive Everglades Restoration Plan; Restoration Coordination and Verification Program, c/o United States Army Corps of Engineers: Jacksonville, FL, USA; South Florida Water Management District: West Palm Beach, FL, USA, 2010.

55. Landry, J.B. Changes in the distribution and density of Florida Bay Macrophytes: 1995-2004. Master's Thesis, University of North Carolina Wilmington, Wilmington, NC, USA, 2005.

(C) 2015 by the authors; licensee MDPI, Basel, Switzerland. This article is an open access article distributed under the terms and conditions of the Creative Commons Attribution license (http://creativecommons.org/licenses/by/4.0/). 